\title{
ASK1-P38 Pathway is Important for Anoikis Induced by Microtubule- Targeting Aryl Chloroethylureas
}

\author{
Jessica Fortin ${ }^{1,2,0}$, Alexandre Patenaude ${ }^{1, \bullet}$, Réna G. Deschesnes ${ }^{1}$, Marie-France Côté ${ }^{1}$, Eric Petitclerc ${ }^{1,3}$ and René C.- \\ Gaudreault ${ }^{1,3}$ \\ ${ }^{1}$ Centre de recherche, Unité de Biotechnologie et de Bioingénierie, C.H.U.Q., Hôpital Saint-François d’Assise, 10 rue de l’Espinay, \\ Québec, Québec, Canada. ${ }^{2}$ Faculté de pharmacie, ${ }^{3}$ Faculté de médecine, Université Laval, Sainte-Foy, Québec, Canada. ${ }^{\circ}$ College of \\ pharmacy, University of Arizona, Tucson, AZ.. Medical Biophysics Dept, BC Cancer Research Centre, Vancouver, BC.
}

Received, January 14, 2010; Revised, April 29, 2010; Accepted, May11, 2010; Published, May 19, 2010.

\begin{abstract}
Purpose. We investigated the involvement of MAPK signaling in the cell death mechanisms of classical microtubule interfering agents (MIA) and aryl-3-(2-chloroethyl)ureas (CEU) acting as antimitotics, along with CEU that don't affect directly microtubules (non-MIA CEU). Methods. To ascertain the activated signaling pathway profile of MIA and non-MIA CEU, Western blot, immunoprecipitation and transfection experiments were performed. Results. Non-MIA CEU do not activate p38, as opposed to MIA, and the extent of ERK and JNK activation is lower than in response to MIA. The effect of MIA and non-MIA CEU on focal adhesion associated protein was also studied; MIA were shown to induce focal adhesion dismantlement associated with a sustained increase in paxillin phosphorylation and FAK cleavage, as opposed to non-MIA CEU. In addition, bcl-2 phosphorylation and AKT cleavage, induced by all MIA tested, was not observed in response to non-MIA CEU further emphasizing the differential cell death mechanisms induced by MIA and non-MIA CEU. Pharmacologic and genetic approaches emphasize that the ASK1-p38 pathway activation contributes to the cytotoxic mechanism of MIA, in contrast to nonMIA CEU. ASK1-p38 is important for increased paxillin phosphorylation and FAK cleavage, suggesting that ASK-1-p38 is an upstream event of FA structure dismantlement induced by MIA. Moreover, the endogen inhibitor of ASK-1, thioredoxin, is released from ASK-1 in response to MIA as opposed to nonMIA CEU. Conclusions. Our study supports that ASK1-p38 activation is an important signaling event, induced by MIA, which impairs focal adhesion structure and induces anchorage-dependent apoptosis or anoikis.
\end{abstract}

\section{INTRODUCTION}

Microtubule polymerization turnover plays an essential role in cell division. Therefore agents that interfere with this dynamics are widely used as chemotherapeutics. Tubulin-polymerization inhibitors such as vinca alkaloids and microtubule-stabilizing agents such as taxus alkaloids inhibit cell cycle progression in $\mathrm{G}_{2} / \mathrm{M}$ phase and later provoke cell death pathways (1-5). Both classes of microtubule-interfering agents (MIA) involve notably the increase in bcl-2 phosphorylation (1, 6-7). Increased phosphorylation of specific residues such as serine 70 of bcl-2 impairs its anti-apoptotic activity (8) though notably impinging its ability to heterodimerize with Bax (9).

The c-jun N-terminal kinases (JNK), extracellular signal-regulated kinase (ERK1/2) and p38 constitute three major MAPK pathways (10). JNK and p38 pathways are both activated during apoptosis induced by different stress conditions such as DNA damage, induced by chemotherapeutics or ultraviolet irradiation (11). In contrast, the ERK1/2 sustained activation is associated with the stimulation of tumor cell proliferation (12). MAPK are of utmost importance for outside-in signaling which integrates signaling from ligands binding with their cognate receptor to gene expression modulation. For example, immediate early gene (IEG) expression of c-fos and c-jun, which heterodimerization leads to the formation of the AP-1 transcription factor, is the hallmark of the JNK and ERK MAPK pathways, respectively (13). Furthermore, the JNK pathways were reported to increase the phosphorylation of bcl-2 in either normal mitosis or during the mitotic arrest in $\mathrm{G}_{2} / \mathrm{M}$ induced by MIA $(1,6,8)$.

Corresponding Author: René C.-Gaudreault, Unité des Biotechnologies et de Bioingénierie, C.R.C.H.U.Q, Hôpital Saint-François d'Assise, 10, rue de l'Espinay, Québec, Canada, e-mail: rene.c-gaudreault@crsfa.ulaval.ca (RCG) jfortin@pharmacy.arizona.edu (JF) 
Activation of the apoptosis ASK1, which activates JNK, was shown to be important to increase bcl-2 phosphorylation in $\mathrm{G}_{2} / \mathrm{M}$ phase arrest by MIA (8). ASK-1 is important for the cytotoxic activity of MIA (14-15). However, upstream signals activating ASK1 in response to MIA are still unclear, but a known regulator of ASK1 is the disulphide reducing enzyme thioredoxin-1 (Trx-1) (16).

Aryl-3-(2-chloroethyl)ureas (CEU) inhibit the growth of several tumor cell lines both in vitro and in vivo $(4,17-21)$. CEU are termed "soft" alkylating agents because they do not alkylate DNA but rather target specific proteins such as $\beta_{\mathrm{II}}$-tubulin (17), Trx-1, and the mitochondrial voltage-dependent anion channel (19). In this context, several CEU derivatives covalently binding to $\beta_{\mathrm{II}}$-tubulin and are designated as MIA CEU. CEU were found to acylate the glutamic acid-198 residue of the mouse $\beta_{\mathrm{V}}$-tubulin (22). CEU that exhibit MIA activity disrupt the microtubule network and inhibit the cell cycle progression in $G_{2} / M$ (17). Recent studies suggest that CEU and MIA, such as vinblastine, induce anoikis of cancer cells (23). The dismantlement of the focal adhesion structure by MIA and loss of cell adhesion occurring prior to activation of effector caspases, such as caspase-3, and DNA fragmentation, support anoikis (23). Furthermore, overexpression of the Integrin-Linked kinase (ILK), which is known to protect against anoikis, confers partial protection against MIA (23). A sustained and increased phosphorylation of paxillin was observed early in this time course of events and is believed to be, at least partly, responsible for the focal adhesion impairment in response to microtubule-prolonged stresses (23). Distinctive activation patterns of MAPK pathways were shown to be induced by MIA and to contribute to the increase of paxillin phosphorylation. However, to which extent the activation of the p38, JNK and ERK pathways is important for the cytotoxic activity of MIA is still unclear.

We herein present evidence that the ASK1p38 MAPK pathway contributes to the cytotoxicity of MIA in contrast to non-MIA CEU. Moreover, pharmacological and genetic approaches show that the ASK1-p38 activation pathway, through the release of ASK-1 from thioredoxin-1 its endogenous inhibitor, leads to anoikis. This upstream signaling event induced by MIA increases paxillin phosphorylation and FA dismantlement. The present study aims to evaluate the pharmacological mechanisms triggered by MIA that ultimately lead to cell death. Their mechanism is compared to non-MIA CEUs that target Trx-1 and other key proteins affecting different pathways (19, 24-27), thus emphasizing the high degree of specificity of the two families of compound.

\section{Novelty of The Work}

The present work is distinct from our previous pharmacological study with aryl chloroethylurea (CEU) derivatives. We describe and demonstrate the upstream events leading to anoikis for the CEU that alkylate the $\beta$-tubulin, namely MIA CEU. We also report the impact of new subset of CEU that doesn't alkylate $\beta$-tubulin (non-MIA $\mathrm{CEU}$ ), on the same signaling pathways. Importantly, the prototypical non-MIA CEU bears a slight chemical modification leading to a drastic change of target. This non-MIA CEU, which does not provoke the dismantlement of the cytoskeleton, it rather alkylates the redox signaling protein thioredoxin-1 (TRX-1). Consequently, we hypothesized that the non-MIA CEU will reduce the binding of ASK-1 to Trx-1 and provoke an apoptotic event through the activation of ASK-1. Surprisingly, the dissociation of the heterodimer ASK-1/Trx-1 was observed following cancer cell treatment with a MIA CEU for $24 \mathrm{~h}$. Instead, non-MIA CEU preserve the heterodimer complex of ASK-1 while Trx-1 and the MAPK signaling pathway is not activated. These observations are supported by the fact that a non-MIA CEU pretreatment prior MIA CEU, cisplatin, daunorubicin, 5fluorouracil or vinblastine cancer cell treatment diminishes the phosphorylation of P-p38.

\section{MATERIALS AND METHODS}

\section{Chemicals.}

CEU described here were prepared as published previously (21). Vinblastine sulfate, colchicine, cisplatin, daunorubicin, 5-fluorouracil, PD098059 and SB203580 were purchased from SigmaAldrich (St. Louis, MO). L-JNKI-1 was obtained from Biosource (Camarillo, CA). All drugs were dissolved in DMSO and used, at a final concentration lower than $0.12 \%(\mathrm{v} / \mathrm{v})$ to avoid any cytotoxicity related to the vehicle. The chemicals for electrophoresis were purchased from Bio-Rad (Hercules, CA). 
Cell Lines and Culture.

MCF-7 (human breast carcinoma), MDA-MB-231 (human breast carcinoma), HT1080 (human fibrosarcoma), M21 (human melanoma), were purchased from the American Type Culture Collection (Manassas, VA). HEK293T cells (human embryonic kidney cells) and N2A cells (mouse neuroblastoma) were kindly provided by Dr. J. Landry and Dr. M.-E. Mirault (U. Laval, QC, Canada), respectively. These cells were cultured in DMEM medium supplemented with $2.2 \mathrm{~g} / \mathrm{L}$ sodium bicarbonate, $4.5 \mathrm{~g} / \mathrm{L}$ glucose, 100 $\mu \mathrm{g} / \mathrm{mL}$ streptomycin sulfate $\mathrm{A}, 100 \mathrm{U}$ of penicillin G, $292 \mu \mathrm{g} / \mathrm{mL}$ glutamine, and $5 \%$ bovine calf serum (Hyclone laboratories, Logan, UT) for MDA-MB-231, HT1080 and M21, and $10 \%$ fetal bovine serum (Hyclone laboratories, Logan, UT) for N2A and HEK293T. Cells were maintained in a moisture saturated atmosphere at $37^{\circ} \mathrm{C}$ in $5 \%$ $\mathrm{CO}_{2}$.

\section{Antibodies.}

The mouse anti-paxillin (clone 349, Ab-1) and anti-thioredoxin-1 (clone 2G11) were purchased at BD Transduction Laboratories (Mississauga, ON, Canada). The monoclonal antibody anti- $\beta$ tubulin (clone TUB 2.1) was obtained from Sigma Chemicals (St-Louis, MO). The mouse anti-ASK1 (clone F-9), mouse anti-p-Tyr (PY99), rabbit anti-p-ASK-1 (Ser 83)-R and rabbit anti-Trx (FL105) was from Santa Cruz Biotechnology (Santa Cruz, CA). Mouse anti-FAK (clone 4.47) was purchased from upstate (Lake Placid, NY). Rabbit anti-c-jun/AP-1 (Ab-2) was obtained from Oncogene Science (Cambridge, MA). Rabbit antipaxillin was obtained from Chemicon International (Temecula, CA). Mouse anti-bcl-2 oncoprotein (clone 124) was purchased at Roche (Basel, Switzerland). The anti-rabbit antibodies against the phosphorylated form of ERK1/2 (20G11), JNK (98F2) and p38, Akt (pan) (11E7), and the cleaved caspase-3, -6 , and -7 were all obtained from Cell Signaling Technology (Beverly, MA). The horseradish peroxidaseconjugated anti-mouse IgG and anti-rabbit IgG were provided by GE Healthcare (Little Chalfont, Buckinghamshire, UK).

\section{Transfections.}

The ASK-1 and control siRNA were kindly provided by Dr. J. Landry. Cells were seeded at 5 $\mathrm{X} 10^{5}$ cells per $60 \mathrm{~mm}$ dish and incubated $12 \mathrm{~h}$ at $37^{\circ} \mathrm{C}$. They were next transfected with $50 \mathrm{nM}$ of each siRNA and $1 \mu \mathrm{L} / \mathrm{mL}$ of the Lipofectamine $2000^{\mathrm{TM}}$ reagent according to the manufacturer instructions (Invitrogen Corporation, Burlington, Ontario, Canada). Forty-eight hours posttransfection, cells (3500/well) were seeded in 96well plates and incubated $5 \mathrm{~h}$ at $37{ }^{\circ} \mathrm{C}$. Fresh medium containing DMSO or drug tested was added, and cells were further incubated at $37{ }^{\circ} \mathrm{C}$ for $24 \mathrm{~h}$. Viability tests were then performed as described below.

\section{Cell Viability Assays.}

Resazurin (25 $\mu \mathrm{g} / \mathrm{mL})$ was added to the culture medium of each well for $1 \mathrm{~h}$ at $37^{\circ} \mathrm{C}$. The cell viability was calculated from fluorescence (excitation, $530 \mathrm{~nm}$; emission, $590 \mathrm{~nm}$ ) measured with a FL 600 Reader (Bio-Tek Instruments, Winooski, VT). The data from experiments conducted in triplicate were corrected for the background fluorescence of the medium and were expressed as the mean percentage of fluorescence obtained for control DMSO-treated cells.

\section{Confocal Fluorescence Microscopy.}

M21 cells were seeded at $1 \times 10^{5}$ cells per well in 6 -well plates that contained 22-mm glass coverslips coated with fibronectin $(10 \mu \mathrm{g} / \mathrm{mL})$ and incubated for $24 \mathrm{~h}$ at $37^{\circ} \mathrm{C}$. Tumor cells were incubated either with CEU-022 $(25 \mu \mathrm{M})$, CEU$025(50 \mu \mathrm{M})$, CEU-098 $(25 \mu \mathrm{M})$, cisplatin (25 $\mu \mathrm{M})$, colchicine $(50 \mathrm{nM})$, vinblastine sulfate (50 $\mathrm{nM})$, or DMSO (0.12\%). Afterward, the cells were washed twice with PBS (pH 7.4) and then fixed with $3.7 \%$ formaldehyde in PBS for 20 min. After two washes with PBS, the cells were permeabilized with $0.1 \%$ saponin in PBS and blocked with $3 \%(\mathrm{w} / \mathrm{v})$ BSA in PBS during $1 \mathrm{~h}$ at $37^{\circ} \mathrm{C}$. The cells were then further incubated for 2 $\mathrm{h}$ at $37^{\circ} \mathrm{C}$ with the anti-c-jun polyclonal antibody (Ab-2, Cambridge, MA; 1/100), or Phospho-c-jun (Ser73, Beverly, MA; 1/100) in a solution containing $0.1 \%$ saponin and $3 \%$ BSA in PBS. The cells were washed three times with PBS containing $0.05 \%$ Tween $20^{\mathrm{TM}}$ and incubated $1 \mathrm{~h}$ at $37^{\circ} \mathrm{C}$ into the blocking buffer containing antirabbit IgG Alexa-488 (1:1000), 4',6-diamidino-2phenylindole $(2.5 \mu \mathrm{g} / \mathrm{mL}$ in PBS) to stain the nuclei. Cells were then processed as described above. The cellular distribution of the fluorescent c-jun or P-c-jun was assessed using a Nikon Eclipse E800 microscope (Tokyo, Japan). Images were captured as a 16-bit tagged image file format files with a Hamamatsu ORCA ER cooled (-20 ${ }^{\circ} \mathrm{C}$ ) digital camera (Photonics Management Corp., Bridgewater, NJ) driven by SimplePCI AIC software (Compix Inc. C Imaging Systems, Cramberry Township, PA). 
Western blot analysis.

Prior to drug exposure, approximately $5 \times 10^{5}$ M21 human melanoma cells were seeded into 6well plates and incubated for $12 \mathrm{~h}$. Exponentially growing M21 human melanoma cells were incubated in the presence of the test compound at the concentrations used above, except for controls, for various periods up to $48 \mathrm{~h}$ at $37^{\circ} \mathrm{C}$. After the treatments, floating and adherent M21 cells were pooled, washed with ice-cold PBS, and then lysed in $100 \mu \mathrm{L}$ Laemmli sample buffer $1 \mathrm{X}$. The cell extracts were boiled for 5 min. The protein concentrations were determined with the Lowry method. Equal amounts of lysate (20 $\mu \mathrm{g}$ of protein) were subjected to electrophoresis using $0.1 \%$ SDS, $7.5 \%$ (ASK-1), $8.5 \%$ (paxillin), or 10 $\%$ polyacrylamide gels. Proteins were transferred onto nitrocellulose membrane. The membranes were incubated with TBSMT (TBS, pH 7.4, $5 \%$ fat-free dry milk or BSA or TBST and $0.1 \%$ Tween-20 ${ }^{\mathrm{TM}}$ ) for $1 \mathrm{~h}$ at $37{ }^{\circ} \mathrm{C}$, and then with either the c-jun (1:100), $\beta$-tubulin (1:500), NF-кB (1:100), p-Tyr (1:500), FAK (1:2500), or paxillin (1:2000) primary antibodies for $12 \mathrm{~h}$ at $4{ }^{\circ} \mathrm{C}$ in a solution of $5 \%$ fat-free dry milk. Blotting with that anti-bcl-2 antibody was performed at a dilution $1: 40$ in TBS for $12 \mathrm{~h}$ at $4{ }^{\circ} \mathrm{C}$. Immunoblotting with ASK-1 (1:50), caspase-6 (1:500), caspase-9 (1:500), Akt (1:1000), p-ASK 1 (Ser 83)-R (1:1000), phospho-p38 (1:1000), phospho-JNK (1:1000), phospho-ERK1/2 (1:1000), caspase-3 (1:1000), or caspase-7 (1:1000) primary antibody was performed for 12 $\mathrm{h}$ at $4{ }^{\circ} \mathrm{C}$ in a solution of $5 \%$ BSA. Membranes were washed with TBST and incubated with 1:2500 peroxidase-conjugated anti-mouse or antirabbit immunoglobulin in TBSMT for $1 \mathrm{~h}$ at room temperature. After washing the membranes with TBST, detection of the immunoblot was carried out using an enhanced chemiluminescence (ECL) detection reagent kit.

\section{Cell viability analysis with propidium iodide.}

Transfected HT-1080 with control or ASK-1 siRNA $\left(1 \times 10^{6}\right)$ were seeded in a $100 \mathrm{~mm}$ petri dish. Controls, CEU-022 (37.5 $\mu \mathrm{M})$ or colchicine (37.5 nm) were incubated for $24 \mathrm{~h}$, the cells were harvested by collecting both the supernatant and the lifted adherent cells. Adherent and floating cells were separately resuspended in $0.5 \mathrm{~mL}$ of DMEM and propidium iodide $(5 \mu \mathrm{g} / \mathrm{ml})$ was added. Cell viability was analyzed using an Epics Elite EPS flow cytometer (Coulter Corporation, Miami, FL).
Immunoprecipitation of paxillin.

Approximately $2 \times 10^{6}$ M21 human melanoma cells were seeded into $100 \mathrm{~mm}$ dishes and incubated for $24 \mathrm{~h}$. Exponentially growing cells were incubated in the presence of $25 \mu \mathrm{M}$ of CEU22 or DMSO for $24 \mathrm{~h}$. After treatment, floating and adherent M21 cells were pooled, washed with ice-cold PBS, and then lysed for $15 \mathrm{~min}$ on ice in $500 \mu \mathrm{L}$ RIPA sample buffer (2 \% NP-40 ${ }^{\mathrm{TM}}$, $2 \%$ sodium deoxycholate, $0.2 \%$ SDS, $0.3 \mathrm{M} \mathrm{NaCl}$, $100 \mathrm{mM}$ Tris $\mathrm{HCl} \mathrm{pH} \mathrm{7.4,} 4$ mM EDTA, $8 \mathrm{mM}$ EGTA, $100 \mathrm{mM} \mathrm{NaF}, 0.4 \mathrm{mM} \mathrm{Na}_{3} \mathrm{VO}_{4}, 0.2 \mathrm{mM}$ PMSF, $4 \mu \mathrm{g} / \mathrm{mL}$ aprotinin and $4 \mu \mathrm{g} / \mathrm{mL}$ leupeptin). Following centrifugation (13 $000 \mathrm{rpm}$, $15 \mathrm{~min}, 4^{\circ} \mathrm{C}$ ), the protein samples were precleared by incubation with normal rabbit IgG (0.5 $\mu g)$ and protein $A / G$ plus Sepharose ${ }^{\mathrm{TM}}(20 \mu \mathrm{L}$, ImmunoPure ${ }^{\circledR}$ Immobilized) for $1 \mathrm{~h}$ at $4{ }^{\circ} \mathrm{C}$ with constant mixing. The Sepharose was pelleted by centrifugation at $4{ }^{\circ} \mathrm{C}(10 \mathrm{~min}, 13000 \mathrm{rpm})$ and the supernatant transferred to a clean tube. Rabbit anti-paxillin $(5 \mu \mathrm{L} / \mathrm{mL})$ was added and samples incubated with mixing for $2 \mathrm{~h}$ at $4{ }^{\circ} \mathrm{C}$. Protein A/G plus Sepharose $(20 \mu \mathrm{L})$ was added and samples incubated for $2 \mathrm{~h}$ at $4{ }^{\circ} \mathrm{C}$ with constant mixing. The Sepharose was pelleted by centrifugation at $4{ }^{\circ} \mathrm{C}(10 \mathrm{~min}, 13000 \mathrm{rpm})$ and washed three times with RIPA buffer $(0.5 \mathrm{~mL}$, without SDS). Following the final wash, pellets were re-suspended in Laemmli sample buffer $1 \mathrm{X}$ (20 $\mu \mathrm{L}$ ), boiled for $3 \mathrm{~min}$ and a $10 \mu \mathrm{L}$ aliquot used to perform Western blotting as described earlier.

\section{Immunoprecipitation and co-immuno- precipitation of thioredoxin.}

The cell treatment procedure was identical than the immunoprecipiration of paxillin. After drug treatment, floating and adherent M21 cells were pooled, washed in ice-cold PBS, and then lysed in $500 \mu \mathrm{L}$ lysis sample buffer (1 mM DTT, $1.25 \mathrm{mM}$ $\mathrm{MgCl}_{2}, 100 \mathrm{mM} \mathrm{KCl}, 50 \mathrm{mM}$ Tris $\mathrm{pH} 8,10 \%$ glycerol, 1 mM EDTA, $0.5 \%$ Triton X-100, 0.2 $\mathrm{mM}$ PMSF, $10 \mu \mathrm{g} / \mathrm{mL}$ aprotinin, $10 \mu \mathrm{g} / \mathrm{mL}$ leupeptin and $10 \mu \mathrm{g} / \mathrm{mL}$ pepstatine) for $15 \mathrm{~min}$ on ice. Following further centrifugation (13 000 rpm, $15 \mathrm{~min}, 4^{\circ} \mathrm{C}$ ), protein samples were pre-cleared by incubation with normal rabbit IgG $(2 \mu \mathrm{g})$ and protein A/G plus agarose $(20 \mu \mathrm{L}$, Santa Cruz Biotechnology) for $1 \mathrm{~h}$ at $4{ }^{\circ} \mathrm{C}$ with constant mixing. The agarose was pelleted by centrifugation at $4{ }^{\circ} \mathrm{C}(10 \mathrm{~min}, 13000 \mathrm{rpm})$ and the supernatant transferred into a clean tube. Rabbit anti-thioredoxin (2 $\mu \mathrm{g}, \mathrm{FL}-105$, Santa Cruz Biotechnology) was added and samples incubated 
with mixing for $1 \mathrm{~h}$ at $4{ }^{\circ} \mathrm{C}$. Protein A/G plus agarose $(40 \mu \mathrm{L})$ was added and samples incubated overnight at $4{ }^{\circ} \mathrm{C}$ with constant mixing. The Sepharose was pelleted by centrifugation at $4{ }^{\circ} \mathrm{C}$ (10 min, $13000 \mathrm{rpm}$ ) and washed three times with lysis buffer $(0.5 \mathrm{~mL}$ of $1 \mathrm{mM}$ DTT, $150 \mathrm{mM}$ $\mathrm{NaCl}, 50 \mathrm{mM}$ Tris $\mathrm{pH}$ 8, $1 \mathrm{mM}$ EDTA, $0.5 \%$ Triton X-100 ${ }^{\mathrm{TM}}, 0.2 \mathrm{mM}$ PMSF, $10 \mu \mathrm{g} / \mathrm{mL}$ aprotinin, $10 \mu \mathrm{g} / \mathrm{mL}$ leupeptin and $10 \mu \mathrm{g} / \mathrm{mL}$ pepstatine). Following the final wash, pellets were re-suspended in Laemmli sample buffer $1 \mathrm{X}$ (40 $\mu \mathrm{L}$ ), boiled for $3 \mathrm{~min}$ and a $20 \mu \mathrm{L}$ aliquot used to perform Western blotting as described earlier.

\section{RESULTS}

Effects of MIA and non-MIA CEU on Paxillin Phosphorylation and FAK Cleavage.

Table 1 presents the molecular structure of CEU022, CEU-098 (MIA) and CEU-025 (non-MIA) used in this study. We have previously showed that CEU-022, colchicine and vinblastine induced FA structure disorganization (23). This observation was associated to the early increase and sustained paxillin phosphorylation, as confirmed in Figure 1A. We further demonstrate that paxillin is phosphorylated on serine and significantly on tyrosine residues (Figure 1B). Paxillin phosphorylation is followed by FAK cleavage (Figure 1C), a reminiscent feature of FA structure disassembly (23). As previously observed, FAK cleavage in response to CEU-022 occurs after the onset of paxillin phosphorylation
(Figure 1A, C). In contrast, the non-MIA CEU025 did not activate paxillin phosphorylation (Figure 1A) while triggering only a weak cleavage of FAK (Figure 1C).

\section{Effects of MIA and non-MIA CEU on MAPK pathways activation.}

Our previous study confirmed that MAPK pathways are activated following exposure to MIA, and that both ERK and p38 contribute to the increase of paxillin phosphorylation (23). Herein, we show that ERK and JNK pathways are activated prior to p38 (Figure 2A). In contrast, non-MIA CEU induced a different pattern of MAPK activation. ERK and JNK activation occurs with MIA CEU while non-MIA CEU shows little if any effect. Interestingly, p38 phosphorylation was not activated by non-MIA CEU (Figure 2A). The levels of expression for non-phosphorylated forms of p38, ERK and JNK did not change significantly (Figure 2A).

\section{MAPK Activation Contribute to a Different Extent on the Cytotoxicity and Death Signaling Induced by MIA CEU.}

To assess whether MAPK are linked to MIA or non-MIA CEU-induced apoptosis, M21 cells were pre-treated with SB203580, PD098059, LJNKI-1 and exposed to MIA and non-MIA CEU for $24 \mathrm{~h}$. Afterwards, cell viability was assessed. Interestingly, p38 inhibitor reversed significantly the cytotoxicity of CEU-022 and colchicine on M21 cells (Figure 2B).

Table 1. Growth Inhibition and Alkylation Potency of the MIA CEU-022, -098 and the non-MIA CEU025 on Melanoma Human M21 cells. The concentration inhibiting $50 \%$ of cell growth $\left(\mathrm{GI}_{50}\right)$ of the CEU used in this study is shown. The alkylated $\beta$-tubulin by CEU, represented by a lower mobility form, is detected by Western blot analysis in denaturing conditions and using $\beta$-tubulin antibody. Similar results are obtained using three other different cell lines: HT-29, M21, MCF-7 (data not shown).
CEU-
Structure
$(\mu \mathrm{M})$
$0,8,16,24,36,48 \mathrm{~h}$

$\mathrm{GI}_{50}$

$\beta$-tubulin alkylation

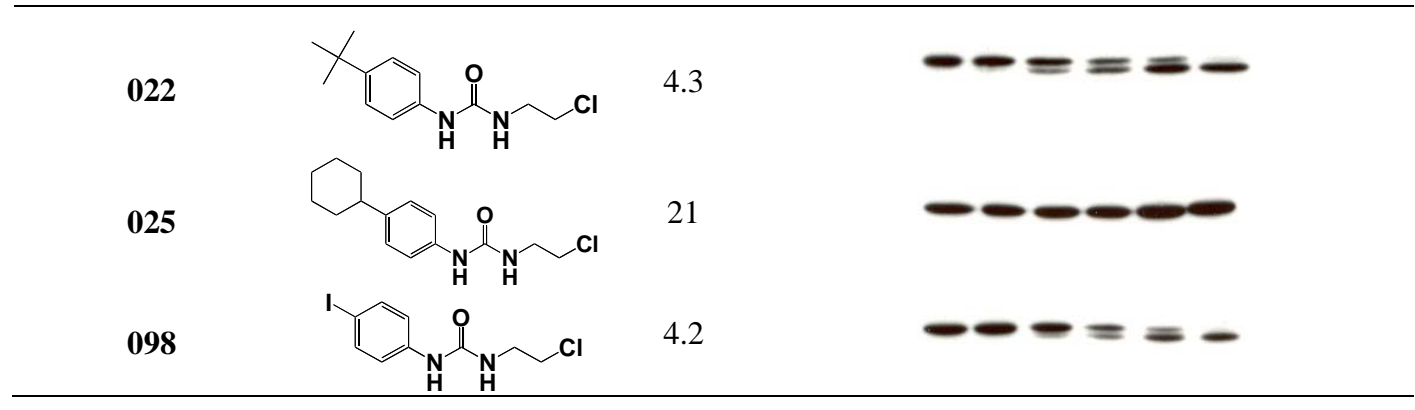



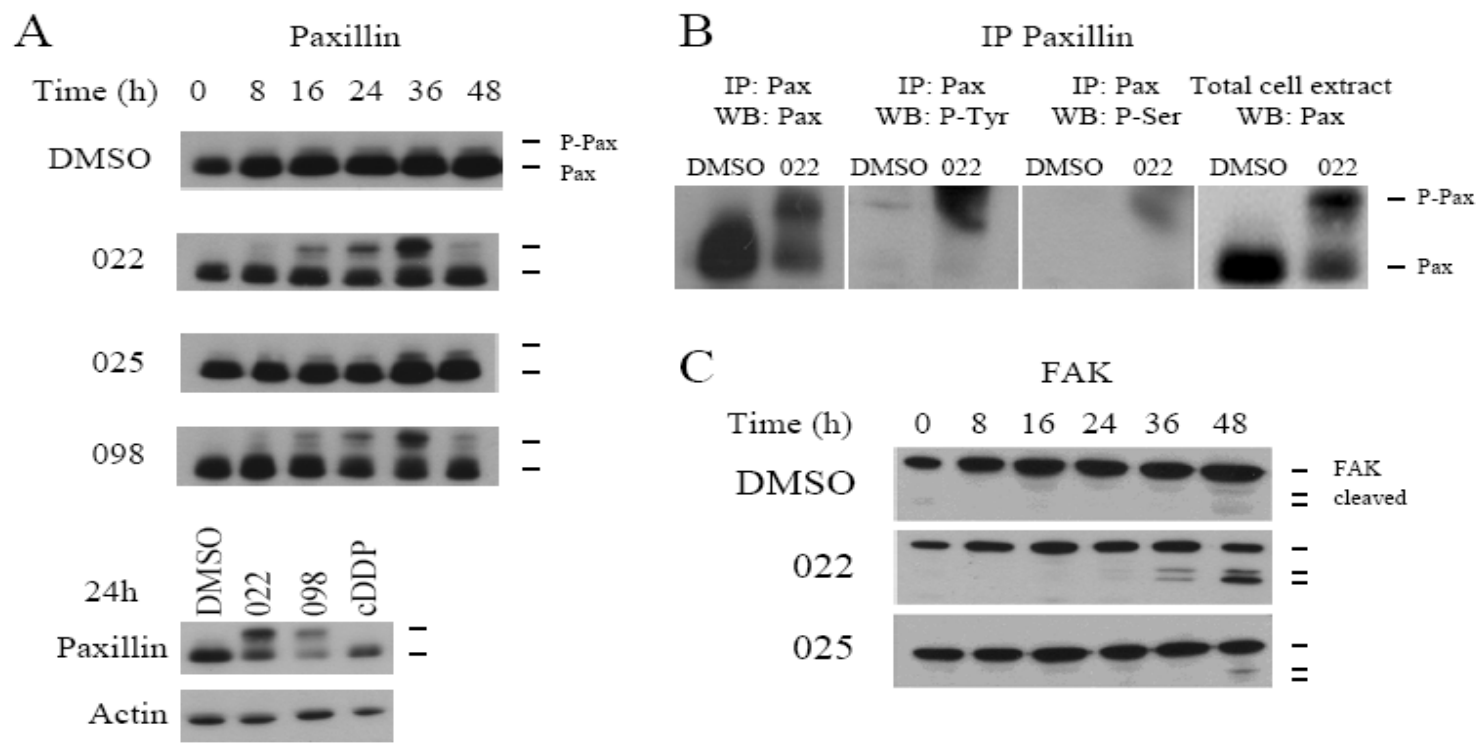

Figure 1. MIA Induced the Phosphorylation of Paxillin and FAK Cleavage. A) and C) M21 cells were treated with DMSO (0.12 \%), CEU-022 (25 $\mu \mathrm{M})$, CEU-098 (25 $\mu \mathrm{M})$, or CEU-025 (50 $\mu \mathrm{M})$ for the indicated time. After treatments, adherent and floating cells were pooled and proteins were extracted prior separation by SDS-PAGE 8.5 or $10 \%$ and Western blot analysis with paxillin or FAK antibodies. Data are representative of two different experiments. Similar results were obtained with MDA-MB-231 cells (data not shown). B) M21 cells were treated with DMSO (0.12 \%) or CEU-022 $(25 \mu \mathrm{M})$ for $24 \mathrm{~h}$. After treatment, proteins from adherent and floating cells were extracted as described in «Material and Methods» and used to immunoprecipitate (IP) paxillin. IP or total protein extract were separated on SDSPAGE $8.5 \%$ and then protein were analyzed by Western blot with anti-paxillin, anti-P-Tyr or anti-P-Ser antibodies. Similar results were obtained with IP of P-Tyr or P-Ser and paxillin Western blot analysis (data not shown).

In contrast, the viability loss induced by our prototypical non-MIA CEU-025 was not decreased in the presence of any of the MAPK inhibitors tested (Figure 2B).

\section{MIA-induced Bcl-2 Phosphorylation and the Cleavage of AKT in Contrast to non-MIA CEU.}

MIA are known to increase bcl-2 phosphorylation through activation of p38 and JNK pathways, leading to apoptosis (8). Bcl-2 phosphorylation diminishes its mobility on PAGE under denaturing conditions in response to colchicine, as depicted in Figure 3A. The phosphorylation of bcl-2 by MIA mainly peaks after $24 \mathrm{~h}$ of treatment (Figure 3A), whereas ERK and JNK were also activated at this time point (Figure 2A). Importantly, MIA and non-MIA CEU induce classical patterns of apoptosis such as PARP cleavage and effector-caspase activation as reported recently (19) and in Figure 4A. Nonetheless, different patterns of caspases or other proteases activation are likely occurring since MIA but not the non-MIA CEU induce the proteolysis of FAK (Figure 1C) and AKT (Figure
3B) that are also two substrates of caspases. Together, these results emphasize the observation that MIA modulates significantly the caspasemediated cell death.

\section{Trx-1/ASK-1 Binding is Decrease by MIA CEU.}

As mentioned, Trx-1 interacts with ASK-1 to inhibit its pro-apoptotic function. Upon stress exposure this interaction is disrupted to allow the kinase activity of ASK-1. We analyzed Trx1ASK1 binding following MIA CEU or non-MIA CEU exposure using immunoprecipitation of Trx1 and co-immunoprecipitation of ASK-1 experiments. Interestingly, the amount of ASK-1 co-immunoprecipitated from cells exposed to CEU-022 using was decreased as compared to DMSO and CEU-025 treatment (Figure 3C). The phosphorylated ASK-1 form was significantly increased after the MIA CEU-022 treatment of the total M21 cell extracts. These results strongly suggest that ASK-1 is indeed ready to activate the apoptotic cascade after its release following a MIA treatment. 
A

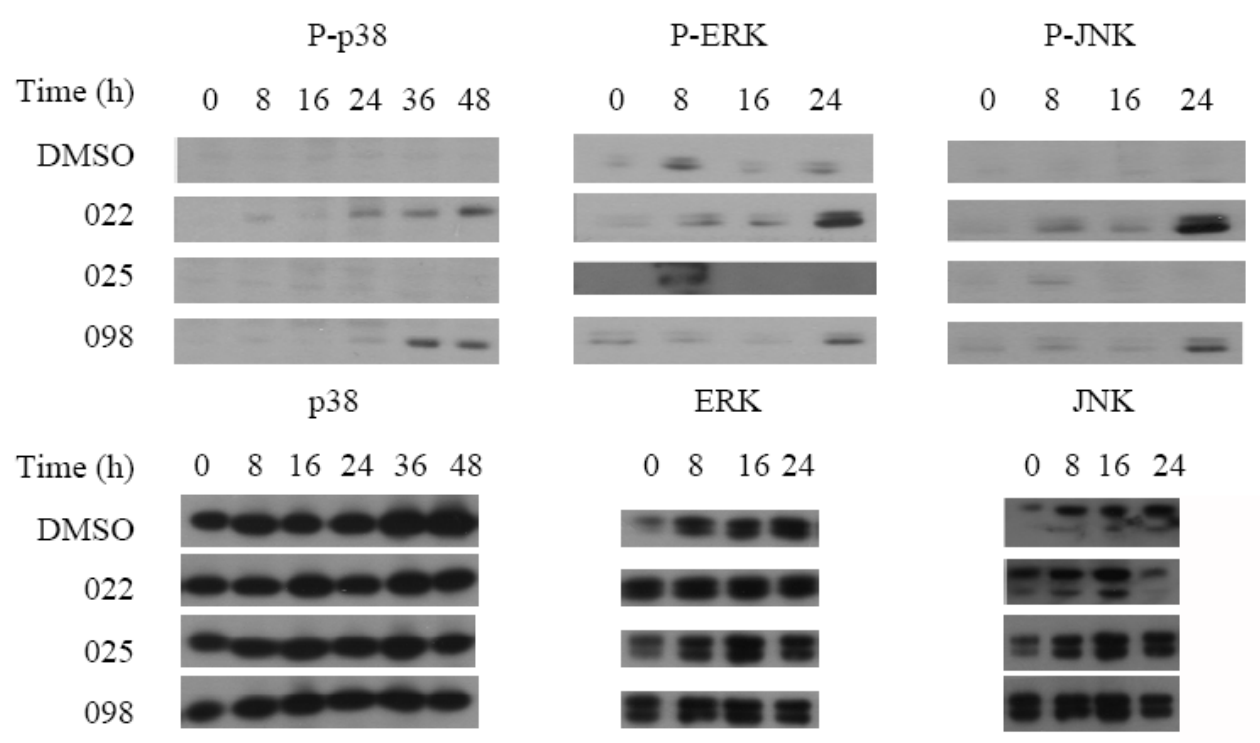

B
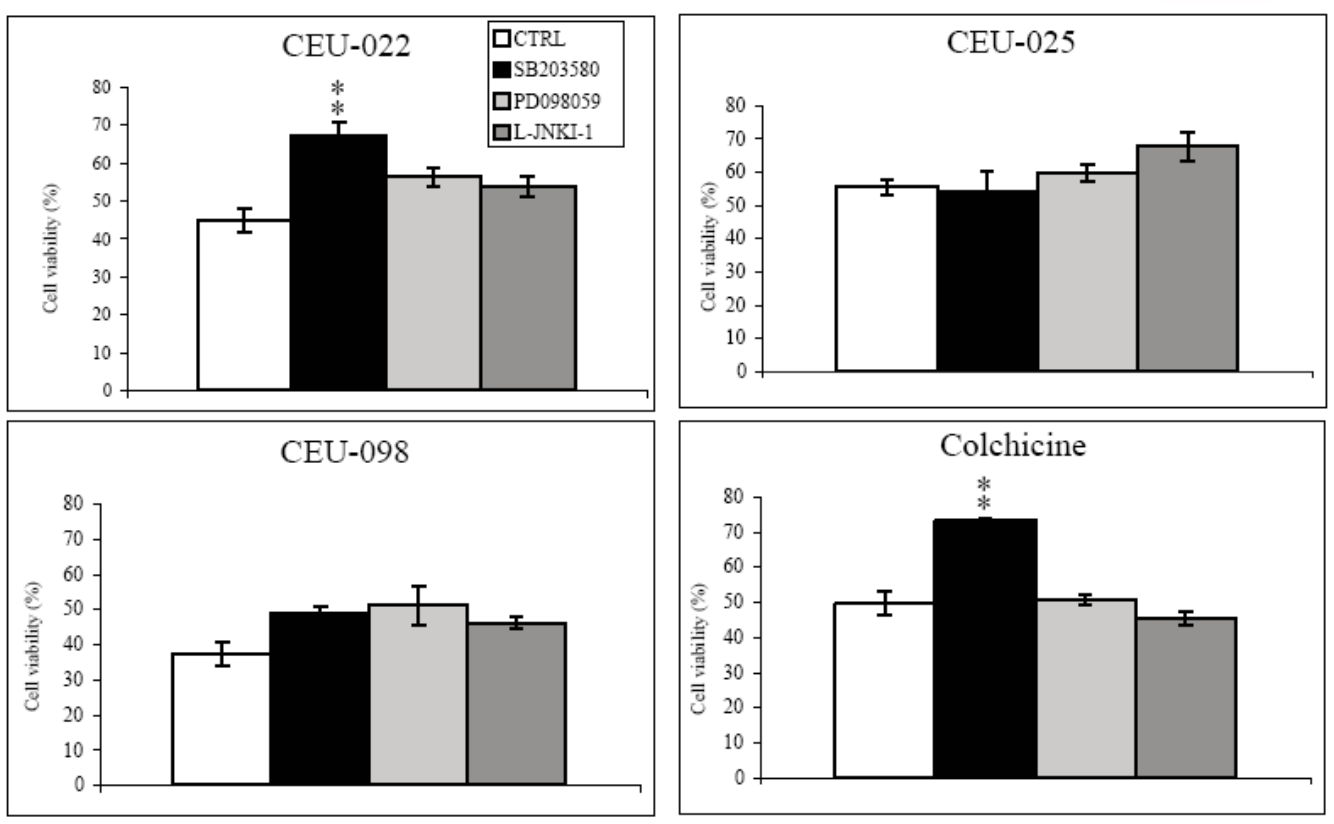

Figure 2. Activation of p38, ERK and JNK by MIA CEU-022 and their Consequences on Cell Viability. A) M21 proteins extracts used in Figure 1 A were separated by SDS-PAGE $10 \%$ and then analyzed by Western blot using antibodies to p38. ERK, JNK and their phosphorylated forms. B) Proliferation assays using M21 cells were performed in the presence of DMSO (0.12\%), MIA CEU-022 (18.75 $\mu \mathrm{M})$, non-MIA CEU-025 (37.5 $\mu$ M) or colchicine (18.75 nM). PD098059 (50 $\mu \mathrm{M}$; ERK), ${ }_{\mathrm{L}}$-JNKI-1 (2 $\mu \mathrm{M}$; JNK), SB203580 (5 $\mu \mathrm{M}$; P38) inhibitors were added to M21 cell cultures $1 \mathrm{~h}$ before the addition of the tested drugs. Resazurin $(25 \mu \mathrm{g} / \mathrm{mL})$ was next added to the culture medium for $1 \mathrm{~h}$ at $37^{\circ} \mathrm{C}$. The cell viability was calculated as described in «Materials and Methods». The analysis of variance (ANOVA) showed significant differences between the control groups and the different MAPK inhibitors for the treatments with CEU-022 and colchicine ( $p<0.01$ for both groups). Consequently, the Dunnet's test for multiple comparisons was performed $(* * \mathrm{p}<0.01)$. 
A

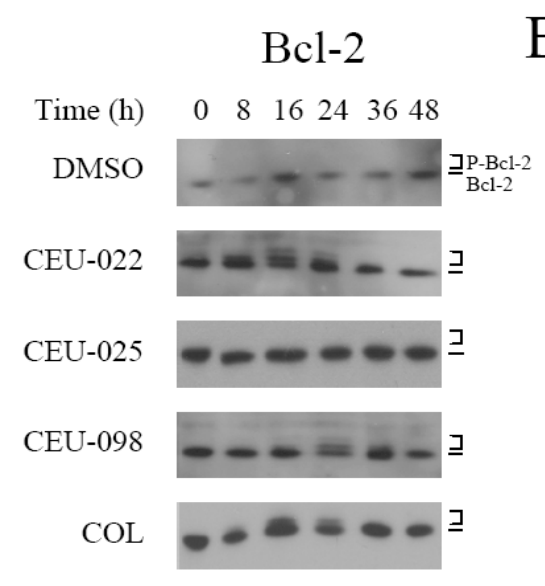

C

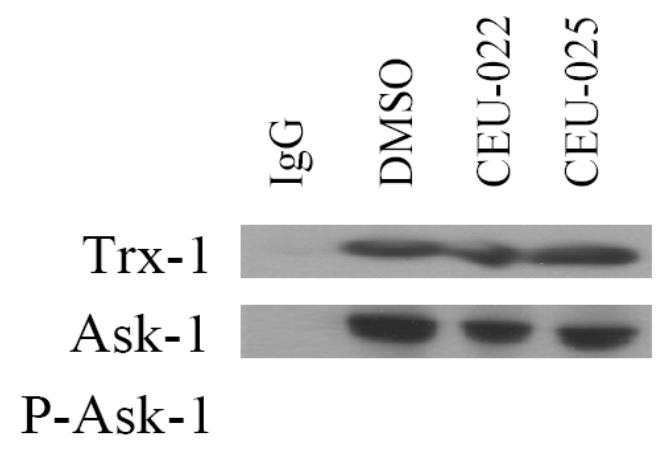

B

Akt

$\begin{array}{llllll}0 & 8 & 16 & 24 & 36 & 48\end{array}$

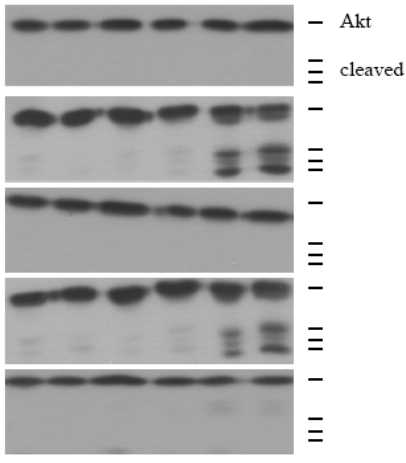

Total cell extract

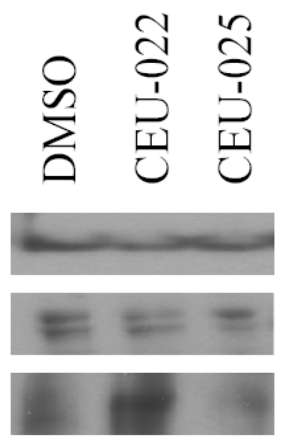

Figure 3. Effects of MIA and non-MIA CEU on AKT Cleavage, the Phosphorylation of bcl-2, and the Interaction of Thioredoxin-1 with ASK-1. M21 proteins extracts used in Figure 1A were separated by SDS-PAGE 10 $\%$ for Western blot analysis of A) AKT and bcl-2 proteins B) M21 cells that were treated with $25 \mu \mathrm{M}$ of CEU-022, 50 $\mu \mathrm{M}$ of CEU-025 or the vehicle (DMSO: $0.12 \%$ ) for $24 \mathrm{~h}$ were lysed and subjected to immunoprecipitation (IP) with a Trx-1 antibody. Total cell extracts and IP proteins were separated using SDS-PAGE and Western blot using the antiTrx-1, Ask-1 or P-Ask-1 antibodies.

\section{ASK-1 is Important for the Cytotoxic Mechanism of MIA CEU.}

We questioned whether ASK-1 influences the signaling of apoptosis and FA dismantlement that follows MIA effects using ASK-1 siRNA. The partial down-regulation of ASK-1 expression, using ASK-1 siRNA was confirmed by Western blot analysis (supplementary data 1). As expected, ASK-1 down-regulation diminished ASK-1 mediated activation of p38 (Figure 4A). Importantly, siRNA of ASK-1 diminished also the paxillin phosphorylation induced by all MIA (Figure 4A). The down regulation of ASK-1 protein expression diminished significantly the cytotoxicity of all MIA tested (Figure 4B) and the viability of the adherent cells (Figure 4C). In addition, the expression of a dominant negative mutant for ASK-1 (ASK1K709M-HA) attenuated significantly the viability loss induced by the MIA CEU-098 when compared to control transfected cells (Figure 4D). The amount of phosphorylated paxillin and the activation of effector caspases (7, 6,3 ) in response to colchicine and MIA CEU were also diminished by ASK-1 siRNA (Figure 4A). Together these results highlight the importance of the activation of the pro-apoptotic protein ASK-1 for the cytotoxic mechanism of MIA. Any significant change in cell viability occurred in response to the non-MIA CEU-025 upon depletion of ASK-1 by siRNA (Figure 4B) and the expression of a negative dominant mutant for ASK-1 activity (ASK1K709M-HA) (Fig 4D), suggesting that ASK1 function is not required for CEU-025-mediated antiproliferative activity and cell death. 
A

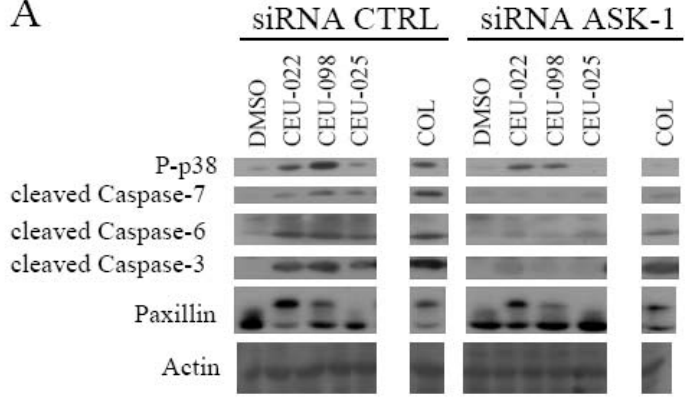

B

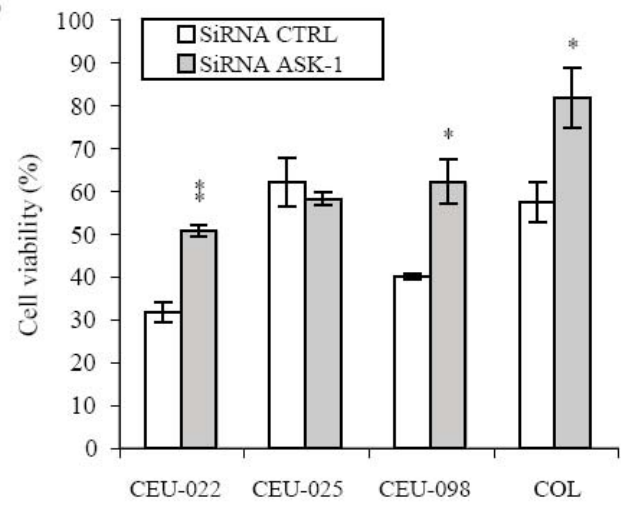

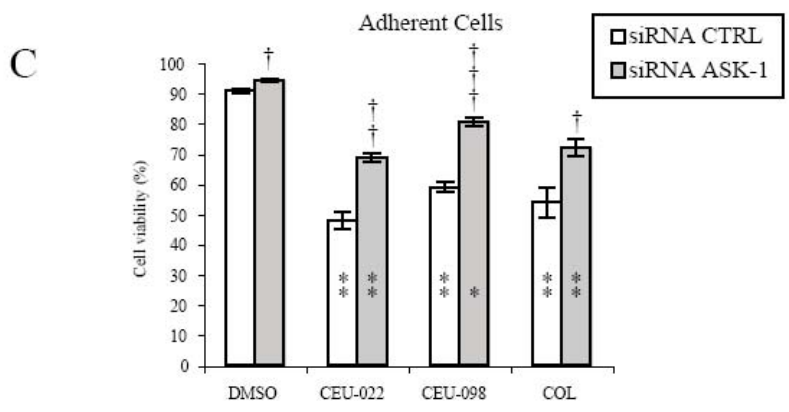

$\mathrm{D}$
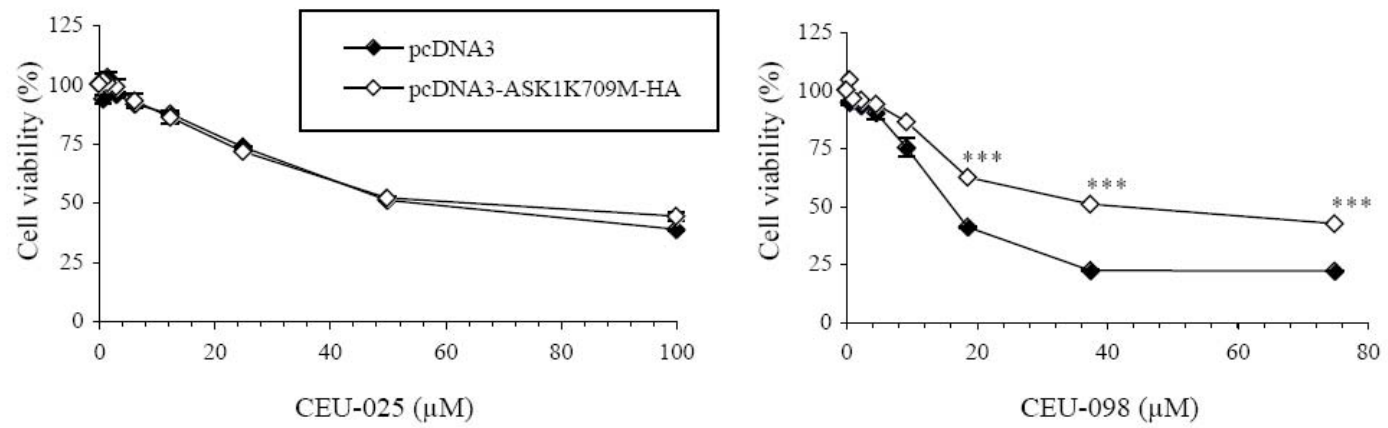

Figure 4. Effect of ASK-1 siRNA on Cytotoxic Responses Induced by CEU and Various Anticancer Agents. A) siRNA-transfected HT1080 cells were plated in a $60 \mathrm{~mm}$ dish $5 \mathrm{~h}$ before the addition of DMSO $(0.12 \% \mathrm{v} / \mathrm{v})$, MIA (colchicine, $50 \mathrm{nM}$; CEU-22, $25 \mu \mathrm{M}$; CEU-098, $25 \mu \mathrm{M}$ ), or the non-MIA CEU-025 (50 $\mu \mathrm{M})$ for $24 \mathrm{~h}$. Protein extracts were separated by $10 \%$ SDS-PAGE before analysis to cleaved caspases (-3, -6, -7), paxilline, FAK, Akt and actin by Western blot. B) Transfected HT1080 cells were plated in a 96-well plate $5 \mathrm{~h}$ before the addition of DMSO (0.12 \%), CEU-022 $(25 \mu \mathrm{M})$, CEU-025 (50 $\mu \mathrm{M})$, CEU-098 $(25 \mu \mathrm{M})$, or colchicine $(50 \mathrm{nM})$ for $24 \mathrm{~h}$. Resazurin $(25 \mu \mathrm{g} / \mathrm{mL})$ was added to the culture medium for $1 \mathrm{~h}$ at $37^{\circ} \mathrm{C}$. The cell viability was calculated as described in «Materials and Methods». The Student t test was performed for the three experiments between the control and ASK-1 siRNA $\left({ }^{* *} \mathrm{p}<0.01,{ }^{*} \mathrm{p}<0.05\right)$. Same results were obtained when using HEK293T. C) Differential cell viability experiments were performed for adherent cell after HT1080 transfection using siRNA for ASK-1 or Controls. After $24 \mathrm{~h}$ treatments with DMSO (0.12 \%) CEU-022 (37.5 $\mu \mathrm{M})$, CEU-098 (37.5 $\mu \mathrm{M})$, or colchicine (37.5 nM), propidium iodide was added to the two cell fractions and FACS analysis was performed. The ANOVA test showed significant differences between the groups $(\mathrm{p}<0.01)$. Consequently, the Dunnet test for multiple comparisons was performed $(\dagger \dagger \dagger p<0.001, \dagger \dagger p<0.01$, $\dagger p<0.05$ ). The Student $t$ test for unpaired groups was performed on control versus treated groups, from three separate experiments $\left({ }^{*} \mathrm{p}<0.05,{ }^{* *} \mathrm{p}<0.01\right)$. D) Transfected N2A cells were plated in a 96 -well plate 5 h before the addition of increasing concentration non-MIA CEU (CEU-025), MIA (CEU-098), or DMSO for $24 \mathrm{~h}$. Resazurin $(25 \mu \mathrm{g} / \mathrm{mL}) \mathrm{was}$ next added to the culture medium for $1 \mathrm{~h}$ at $37^{\circ} \mathrm{C}$. The cell viability was calculated as described in «Materials and Methods». The Student $t$ test for unpaired samples was performed from three separate experiments $\left({ }^{* * *} \mathrm{p}<0.001\right)$. 
A

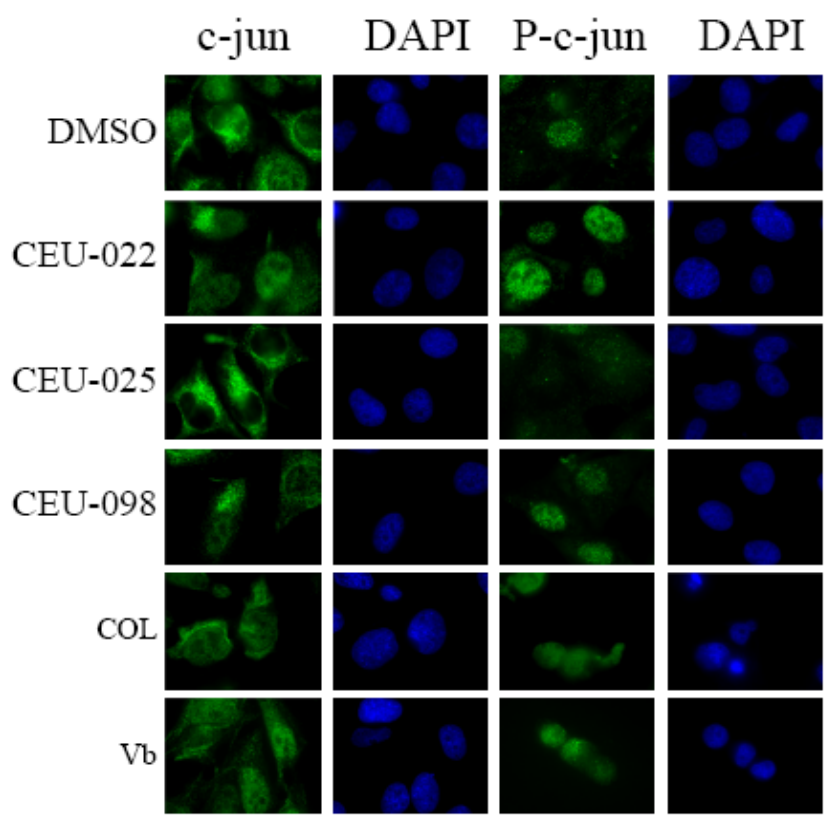

B

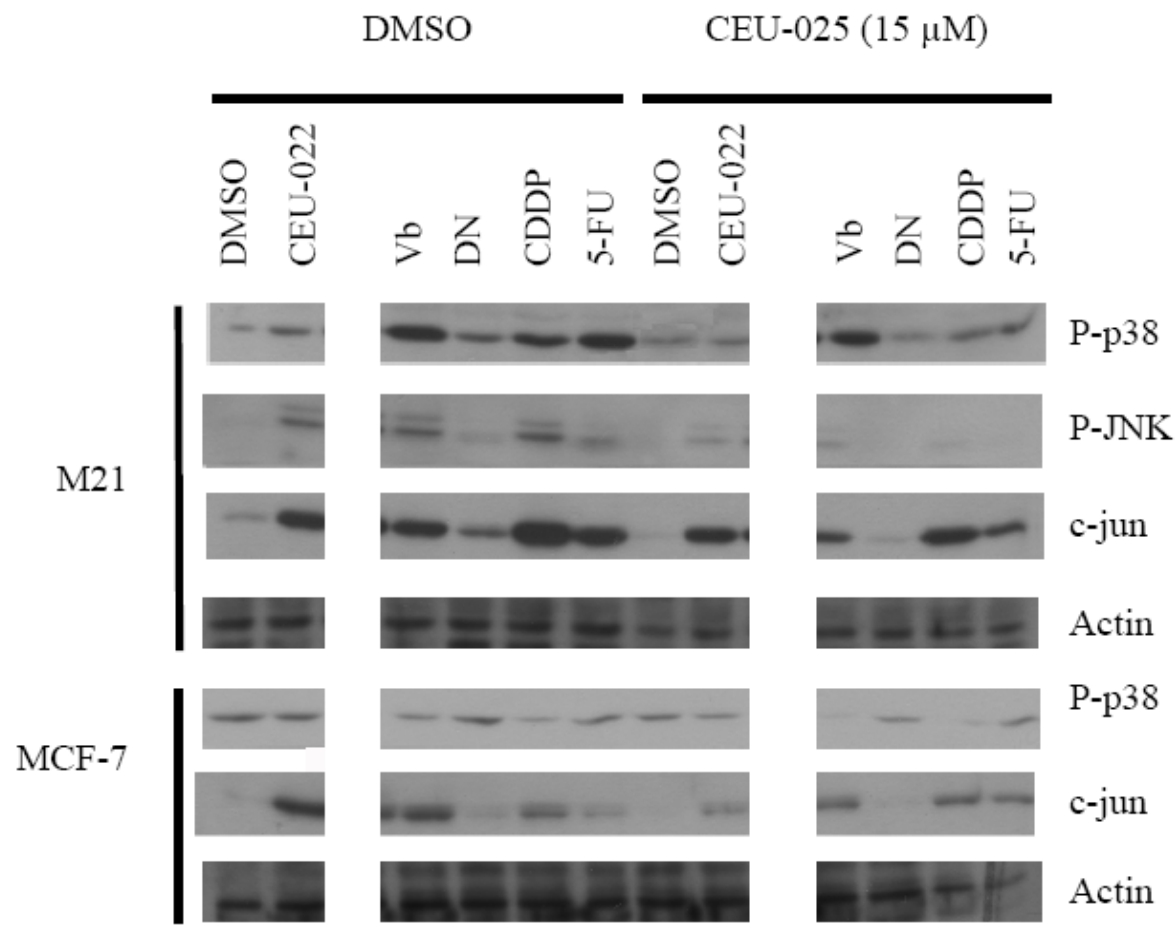

Figure 5. Effect of non-MIA CEU Pre-Treatment on MIA-Mediated MAPKs Activation. A) M21 tumor cells were plated in 6-well dishes and treated the next day for $24 \mathrm{~h}$ with either CEU-022 (25 $\mu \mathrm{M})$, CEU-025 (50 $\mu \mathrm{M})$, CEU-098 (25 $\mu \mathrm{M})$, cisplatin $(25 \mu \mathrm{M})$, colchicine (50 nM), Vb (50 nM), or DMSO (0.12 \%). Cells were fixed, permeabilized and stained with the c-jun or P-c-jun (Ser 73) antibody prior fluorescence-conjugated secondary analysis using standard fluorescence microscopy procedures as described in «Materials and Methods». B) M21 and MCF-7 cells were pretreated with DMSO $(0.04 \%)$ or CEU-025 $(15 \mu \mathrm{M})$ for $16 \mathrm{~h}$ and then with DMSO $(0.04 \%)$ CEU-022 (50 $\mu \mathrm{M})$, Vb $(0.1$ $\mu \mathrm{M})$, DN $(0.5 \mu \mathrm{M})$, cisplatin $(30 \mu \mathrm{M})$ or 5 -FU $(50 \mu \mathrm{M})$ for 24 h. Cells were next harvested for Western blot analysis with the indicated antibody. 
The Non-MIA CEU-025 Antagonizes the Activation of MAPK Pathways Induced by MIA.

Interestingly, non-MIA CEU do not release ASK1 from its endogenous inhibitor, Trx-1, when compared to MIA in cells (Figure 3C). Moreover, a drastic diminution of c-jun and P-c-jun nuclear levels, a downstream hallmark of JNK pathways activation, was observed in response to the nonMIA CEU-025 used in this study (Figure 5A). These results suggest that non-MIA CEU impede basal nuclear translocation of c-jun, presumably through inhibition of its expression and/or phosphorylation. Based on this hypothesis, we questioned whether the non-MIA CEU-025 could also affect drug-induced c-Jun activation by MAPK pathways. To that end, pre-treatment of cells with low doses of CEU-025, that does not affect significantly cell growth, was performed for 16 hours prior to drug exposure. Under these conditions, Figure 5B shows that the p38 and JNK phosphorylation, and interestingly, c-jun expression, were significantly reduced by CEU025 pre-treatment in response to MIA, cisplatin, daunorubicin and 5-fluorouracil. This suggests that CEU-025 can also block drug-induced c-Jun expression/phosphorylation through MAPK inhibition or ASK-1/Trx-1 heterodimerisation.

\section{DISCUSSION}

MAPK pathways have intricate roles in cancer as they are the major crossroads of intracellular signaling for the control of cell functions such proliferation and apoptosis (28). Their dysregulation contributes to the development of cancer and may also influence the activity of antineoplastics such as classical MIA like paclitaxel or vinblastine. It is therefore important to determine the role of MAPK in the anticancer activity of MIA or non-MIA CEU. Our study points out the capacity of CEU that alkylate $\beta_{\mathrm{II}^{-}}$ tubulin and the influence of their covalent binding to $\beta$-tubulin to the selective activation of MAPK pathways. JNK and ERK are activated significantly in response to MIA in contrast to non-MIA CEU compounds. In contrast, p38 is gradually activated by MIA but is unresponsive to non-MIA CEU. In parallel, the activation of ASK1 correlates with the p38 activation induced by MIA. Another finding is that ASK1-p38 MAPK contributes significantly to the antiproliferative activity of MIA in contrast to non-MIA CEU. This was evidenced using two different approaches: ASK-1 siRNA and the pharmacological inhibition of p38 by SB203580. The exposure of M21 and HT1080 cells to any of these agents decreased the antiproliferative activity induced by MIA. In addition, our data point out that ASK1-p38 pathway is also important for the anticancer activity of colchicine and probably other microtubule-interfering agents such as paclitaxel (14). To our knowledge the present study is the first report showing that disruption of the ASK1-p38 pathway impedes the antiproliferative activity of tubulinpolymerization inhibitors.

ASK1 activation results also in the activation of JNK, the stress-activated MAPK pathway. JNK-ASK1 dependent activation in response to MIA was evidenced here using siRNA. In addition, we show that ASK1 down-regulation alters JNK-associated functions since it decreases the nuclear expression and phosphorylation of cjun, the hallmark JNK-regulated gene. MIA and non-MIA CEU exhibit distinctive effects on IEG expressions, which are well known MAPK associated downstream events. In that context, it is noteworthy that ASK-1 phosphorylation was not induced by CEU-025 compared to CEU-022. We believed that non-MIA CEU, through a still unknown mechanism, block ASK-1 activation, resulting in inhibition of JNK and p38 MAPK pathways that correlates with MIA-mediated c-jun nuclear down-regulation and phosphorylation levels. The importance of the induction of c-jun expression for the cytotoxicity of MIA and other MT-interfering agents remains to be clarified. The level of IEG expression was shown to affect the efficacy of anticancer agents. An increase of c-jun expression was found to be associated with the resistance of cells to paclitaxel (29).

Interestingly, non-MIA CEU were shown to arrest cells in $G_{0} / G_{1}$ phase (25-27). Herein, we demonstrated that they inhibit the c-jun translocation to the nucleus. DNA-binding protein jun/fos (AP-1) cannot heterodimerize in the nucleus and consequently accomplishes its function. The activator factor (AP-1) is important for the transcription and for the control of $G_{0} / G_{1}$ transition involving AP-1-responsive cyclin D1 gene (30).

In addition to its involvement in gene expression changes, ASK1 modulates other pathways. For example, the ASK1-JNK pathway increases the phosphorylation of the bcl-2 protein in response to drug-induced microtubule stresses, which blocks the anti-apoptotic function of bcl-2 (8). Our data show the increase of bcl-2 phosphorylation in response to MIA and support 
also that these compounds block the antiapoptotic function of bcl-2. Furthermore, ASK1p38 activation is known to affect the microtubule integrity and their dynamics through different pathways. ASK1-p38 pathway increases the phosphorylation of Op18/Stathmin (31), a soluble protein inducing the depolymerization of microtubules (32). However it remains unclear whether p38 induced phosphorylation of Op18/Stathmin is required for MT depolymerization. Additionally, p38 increases the phosphorylation of paxillin in response to MIA and several MT-targeting agents (23). Herein we have demonstrated that ASK-1 is required in this pathway induced by MIA, suggesting that ASK-1 is an early signaling event connecting druginduced MT stress to FA disorganization. Activation of ASK1 was shown to trigger the mitochondrial-dependant caspase apoptosis pathway (34-36). FAK is a known target of caspase-3 and caspase-6 (34-37). This agrees with our observation that ASK1-siRNA diminished the activation of caspase-3, -6, and -7.

The control of ASK-1 activation is under the regulation of different binding partners, depending on the cell type and the nature of the stress (38). Trx-1 is one of the physiological inhibitors of ASK-1 (16). Trx-1 participates to the regulation of a large number of redox signaling pathways, notably by its Cys32/35 residues that are essential for the Trx-disulfide reducing activity (39). Interestingly, these nucleophilic residues are markedly prone to oxidation by reactive oxygen species (ROS) such hydrogen peroxide $\left(\mathrm{H}_{2} \mathrm{O}_{2}\right)(16,39)$. ASK-1 is activated by intracellular ROS by oxidizing Trx-1 cysteine (Cys 32/35) residues leading to the dissociation of the Trx1-Ask1 complex (16). Our observations that MIA CEU induced ROS production (19) and dissociation of the Trx1-ASK1 complex, raise the hypothesis that ROS-mediated dissociation of Trx-1-ASK1 interaction is an important signaling event of ASK1-mediated cell death in response to MIA. Non-MIA CEU-025 does not trigger apoptosis by ASK-1 signaling pathways despite the fact that this CEU covalently binds to alkylated Trx-1.

Redox equilibrium is a poorly understood but still important aspect of MT function as demonstrated notably with the cysteine residues of tubulin which redox status influence MT polymerization (40-41). Trx-1 has been shown to interact with MT and to reduce disulfide bridges of the $\alpha$-, $\beta$-tubulin heterodimers oxidized by ROS (42). Moreover, the Trx-Trx reductase system was shown to restore the MTpolymerization activity of tau inhibited by peroxinitrite (43). Together these studies support the importance of the redox control homeostasis in the cytoskeleton organization. Whether Trx-1 function is linked to MIA effects on cytoskeleton organization and MAPK induced apoptosis deserve further investigation.

Non-MIA CEU have been shown to covalently bind to Trx-1, mitochondrial voltagedependent anion channel 2 and prohibitin-1 (19, 24-25), whereas MIA CEU target $\beta$-tubulin (17, 22). CEU-025, a prototypical non-MIA CEU, antagonizes MAPK activation triggered by MIA CEU, alkylating (e.g., cisplatin) or intercalating agents (e.g., daunorubicin). Interestingly, immunoprecipitation studies demonstrated the heterodimerization of ASK-1 and Trx-1 in the presence of CEU-025, which is in agreement with MAPK inactivation. Together, these observations suggest that CEU-025 stabilizes by binding to Trx-1 the heterodimeric state of ASK-1 with Trx1. MAPK inhibition by non-MIA CEU raises the issue of considering potential drug combinations. The cytotoxicity of MIA CEU or alkylating agents can be reduced only if the activation of p38 is critical as a threshold to induce apoptosis. However, p38 inhibition experiments showed a slightly increase of cell survival in the presence of CEU-022, suggesting that other pathways might be involved in concert to trigger apoptosis. We believe that the use of MAPK inhibitors might be beneficial for therapeutic combination with MIA and alkylating agents. Pre-existing or inducing homeostasis conditions promoting cell survival and chemotherapeutic resistance involving the activation of ERK and expression of protooncogene cyclin D1 gene can be possible (44). Further studies are required to assess the proper dosage of MAPK activation or threshold that are needed to trigger the apoptotic pathway.

Our study underlines the importance of ASK1-p38 pathways for the antiproliferative and the pro-apoptotic activities of MIA. In addition, it shows also that FA structure dismantlement induced by these agents is downstream of ASK1 signaling. How the microtubule stress, induced by MIA, is connected to ASK-1 activation remains to be elucidated. Our results also suggest that the Trx-1 redox signaling protein is potentially involved in this connection. 


\section{ACKNOWLEDGMENT}

This work was supported by grants from le Fonds de la Recherche en Santé du Québec, Junior II (E. P.) and Canadian Institute for Health Research (R.C-G, E. P.; grant \#MOP-79334). Jessica S. Fortin is recipient of a studentship from the Fonds de la Recherche en Santé du Québec. We are very grateful to Mr. Jacques Lacroix for technical support, Mrs. Josée Boulet for the conception of some of the illustrations and Mr. John Fitch for proofreading the final version of the manuscript. We also thank Dr. Jacques Landry and Philippe Nadeau for providing essential reagents and helpful discussions.

\section{REFERENCES}

1. Fan M, Goodwin M, Vu T, Brantley-Finley C, Gaarde WA and Chambers TC. Vinblastineinduced phosphorylation of $\mathrm{Bcl}-2$ and $\mathrm{Bcl}-\mathrm{XL}$ is mediated by JNK and occurs in parallel with inactivation of the Raf-1/MEK/ERK cascade. J Biol Chem, 2000; 275(39):29980-29985.

2. Hadfield JA, Ducki S, Hirst N and McGown AT. Tubulin and microtubules as targets for anticancer drugs. Prog Cell Cycle Res, 2003; 5:309-325.

3. Mani S, Macapinlac M, Jr., Goel S, VerdierPinard D, Fojo T, Rothenberg M and Colevas D. The clinical development of new mitotic inhibitors that stabilize the microtubule. Anticancer Drugs, 2004; 15(6):553-558.

4. Moreau E, Fortin S, Desjardins M, Rousseau JL, Petitclerc E and C.-Gaudreault R. Optimized Nphenyl-N'-(2-chloroethyl)ureas as potential antineoplastic agents: Synthesis and growth inhibition activity. Bioorg Med Chem, 2005; 13(24):6703-6712.

5. Prinz H. Recent advances in the field of tubulin polymerization inhibitors. Expert Rev Anticancer Ther, 2002; 2(6):695-708.

6. Fan M, Du L, Stone AA, Gilbert KM and Chambers TC. Modulation of mitogen-activated protein kinases and phosphorylation of $\mathrm{Bcl}-2$ by vinblastine represent persistent forms of normal fluctuations at G2-M1. Cancer Res, 2000; 60(22):6403-6407.

7. Srivastava RK, Mi QS, Hardwick JM and Longo DL. Deletion of the loop region of Bcl-2 completely blocks paclitaxel-induced apoptosis. Proc Natl Acad Sci U S A, 1999; 96(7):37753780.

8. Yamamoto K, Ichijo H and Korsmeyer SJ. BCL-2 is phosphorylated and inactivated by an ASK1/Jun N-terminal protein kinase pathway normally activated at G(2)/M. Mol Cell Biol, 1999; 19(12):8469-8478.

9. Ito T, Deng X, Carr B and May WS. Bcl-2 phosphorylation required for anti-apoptosis function. J Biol Chem, 1997; 272(18):1167111673.

10. Johnson GL and Lapadat R. Mitogen-activated protein kinase pathways mediated by ERK, JNK, and p38 protein kinases. Science, 2002; 298(5600):1911-1912.

11. Dent P, Yacoub A, Fisher PB, Hagan MP and Grant S. MAPK pathways in radiation responses. Oncogene, 2003; 22(37):5885-5896.

12. McCubrey JA, Steelman LS, Chappell WH, Abrams SL, Wong EW, Chang F, Lehmann B, Terrian DM, Milella M, Tafuri A, Stivala F, Libra M, Basecke J, Evangelisti C, Martelli AM and Franklin RA. Roles of the Raf/MEK/ERK pathway in cell growth, malignant transformation and drug resistance. Biochim Biophys Acta, 2007; 1773(8):1263-1284.

13. Turjanski AG, Vaque JP and Gutkind JS. MAP kinases and the control of nuclear events. Oncogene, 2007; 26(22):3240-3253.

14. Marone M, D'Andrilli G, Das N, Ferlini C, Chatterjee S and Scambia G. Quercetin abrogates taxol-mediated signaling by inhibiting multiple kinases. Exp Cell Res, 2001; 270(1):1-12.

15. Wang TH, Popp DM, Wang HS, Saitoh M, Mural JG, Henley DC, Ichijo $\mathrm{H}$ and Wimalasena J. Microtubule dysfunction induced by paclitaxel initiates apoptosis through both c-Jun N-terminal kinase (JNK)-dependent and -independent pathways in ovarian cancer cells. J Biol Chem, 1999; 274(12):8208-8216.

16. Saitoh M, Nishitoh H, Fujii M, Takeda K, Tobiume K, Sawada Y, Kawabata M, Miyazono K and Ichijo H. Mammalian thioredoxin is a direct inhibitor of apoptosis signal-regulating kinase (ASK) 1. Embo J, 1998; 17(9):2596-2606.

17. Legault J, Gaulin JF, Mounetou E, Bolduc S, Lacroix J, Poyet $\mathrm{P}$ and C.-Gaudreault R. Microtubule disruption induced in vivo by alkylation of beta-tubulin by 1-aryl-3-(2chloroethyl)ureas, a novel class of soft alkylating agents. Cancer Res, 2000; 60(4):985-992.

18. Petitclerc E, Deschesnes RG, Cote MF, Marquis C, Janvier R, Lacroix J, Miot-Noirault E, Legault J, Mounetou E, Madelmont JC and C.-Gaudreault R. Antiangiogenic and antitumoral activity of phenyl-3-(2-chloroethyl)ureas: a class of soft alkylating agents disrupting microtubules that are unaffected by cell adhesion-mediated drug resistance. Cancer Res, 2004; 64(13):4654-4663.

19. Patenaude A, Deschesnes RG, Rousseau JL, Petitclerc E, Lacroix J, Cote MF and R CG. New Soft Alkylating Agents with Enhanced Cytotoxicity against Cancer Cells Resistant to Chemotherapeutics and Hypoxia. Cancer Res, 2007; 67(5):2306-2316.

20. Fortin S, Wei L, Moreau E, Labrie P, Petitclerc E, Kotra LP, C-Gaudreault R. Mechanism of action of N-phenyl-N'-(2-chloroethyl)ureas in the colchicine-binding site at the interface between 
alpha- and beta-tubulin. J Med Chem, 2009; 17(10):3690-7.

21. Fortin JS, Lacroix J, Desjardins M, Patenaude A, Petitclerc E and R CG. Alkylation potency and protein specificity of aromatic urea derivatives and bioisosteres as potential irreversible antagonists of the colchicine-binding site. Bioorg Med Chem, 2007; 15(13):4456-4469.

22. Bouchon B, Chambon C, Mounetou E, Papon J, Miot-Noirault E, Gaudreault RC, Madelmont JC and Degoul F. Alkylation of beta-tubulin on Glu 198 by a microtubule disrupter. Mol Pharmacol, 2005; 68(5):1415-1422.

23. Deschesnes RG, Patenaude A, Rousseau JL, Fortin JS, Ricard C, Cote MF, Huot J, R CG and Petitclerc E. Microtubule-destabilizing agents induce focal adhesion structure disorganization and anoikis in cancer cells. J Pharmacol Exp Ther, 2007; 320(2):853-864.

24. Bouchon B, Papon J, Communal Y, Madelmont JC and Degoul F. Alkylation of prohibitin by cyclohexylphenyl-chloroethyl urea on an aspartyl residue is associated with cell cycle G(1) arrest in B16 cells. Br J Pharmacol, 2007; 152(4):449-455.

25. Fortin JS, Cote MF, Lacroix J, Desjardins M, Petitclerc E and R CG. Selective alkylation of beta(II)-tubulin and thioredoxin-1 by structurally related subsets of aryl chloroethylureas leading to either anti-microtubules or redox modulating agents. Bioorg Med Chem, 2008; 16(15):7277-90.

26. Fortin JS, Cote MF, Lacroix J, Patenaude A, Petitclerc E and R CG. Cycloalkyl-substituted aryl chloroethylureas inhibiting cell cycle progression in G0/G1 phase and thioredoxin-1 nuclear translocation. Bioorg Med Chem Lett, 2008; 18(12):3526-3531.

27. Fortin JS, Cote MF, Lacroix J, Petitclerc E and R CG. Aromatic 2-chloroethyl urea derivatives and bioisosteres. Part 2: Cytocidal activity and effects on the nuclear translocation of thioredoxin-1, and the cell cycle progression. Bioorg Med Chem, 2008; 16(15):7277-90.

28. Dhillon AS, Hagan S, Rath O and Kolch W. MAP kinase signalling pathways in cancer. Oncogene, 2007; 26(22):3279-3290.

29. Masanek U, Stammler G and Volm M. Messenger RNA expression of resistance proteins and related factors in human ovarian carcinoma cell lines resistant to doxorubicin, taxol and cisplatin. Anticancer Drugs, 1997; 8(2):189-198.

30. Tashiro E, Tsuchiya A, Imoto M. Functions of cyclin D1 as an oncogene and regulation of cyclin D1 expression. Cancer Science, 2007; 98(5):62935.

31. Mizumura K, Takeda K, Hashimoto S, Horie T and Ichijo H. Identification of Op18/stathmin as a potential target of ASK1-p38 MAP kinase cascade. J Cell Physiol, 2006; 206(2):363-370.

32. Andersen SS. Spindle assembly and the art of regulating microtubule dynamics by MAPs and
Stathmin/Op18. Trends Cell Biol, 2000; 10(7):261-267.

33. Grossmann J, Artinger M, Grasso AW, Kung HJ, Scholmerich J, Fiocchi $\mathrm{C}$ and Levine AD. Hierarchical cleavage of focal adhesion kinase by caspases alters signal transduction during apoptosis of intestinal epithelial cells. Gastroenterology, 2001; 120(1):79-88.

34. Grossmann J. Molecular mechanisms of "detachment-induced apoptosis--Anoikis". Apoptosis, 2002; 7(3):247-260.

35. Schmidmaier R, Mandl-Weber S, Gaul L, Baumann P, Bumeder I, Straka C and Emmerich B. Inhibition of lymphocyte function associated antigen 1 by LFA878 induces apoptosis in multiple myeloma cells and is associated with downregulation of the focal adhesion kinase/phosphatidylinositol 3 kinase/Akt pathway. Int J Oncol, 2007; 31(4):969-976.

36. Hatai T, Matsuzawa A, Inoshita S, Mochida Y, Kuroda T, Sakamaki K, Kuida K, Yonehara S, Ichijo $\mathrm{H}$ and Takeda K. Execution of apoptosis signal-regulating kinase 1 (ASK1)-induced apoptosis by the mitochondria-dependent caspase activation. J Biol Chem, 2000; 275(34):2657626581.

37. Wen LP, Fahrni JA, Troie S, Guan JL, Orth K and Rosen GD. Cleavage of focal adhesion kinase by caspases during apoptosis. J Biol Chem, 1997; 272(41):26056-26061.

38. Tobiume K, Matsuzawa A, Takahashi T, Nishitoh H, Morita K, Takeda K, Minowa O, Miyazono K, Noda T, Ichijo H. ASK1 is required for sustained activations of JNK/p38 MAP kinases and apoptosis. EMBO rep, 2001; 2(3):222-228.

39. Lillig $\mathrm{CH}$ and Holmgren A. Thioredoxin and related molecules from biology to health and disease. Antioxid Redox Signal, 2007; 9(1):25-47.

40. Luduena RF and Roach MC. Tubulin sulfhydryl groups as probes and targets for antimitotic and antimicrotubule agents. Pharmacol Ther, 1991; 49(1-2):133-152.

41. Shan B, Medina JC, Santha E, Frankmoelle WP, Chou TC, Learned RM, Narbut MR, Stott D, Wu P, Jaen JC, Rosen T, Timmermans PB and Beckmann H. Selective, covalent modification of beta-tubulin residue Cys-239 by T138067, an antitumor agent with in vivo efficacy against multidrug-resistant tumors. Proc Natl Acad Sci U S A, 1999; 96(10):5686-5691.

42. Khan IA and Luduena RF. Possible regulation of the in vitro assembly of bovine brain tubulin by the bovine thioredoxin system. Biochim Biophys Acta, 1991; 1076(2):289-297.

43. Landino LM, Skreslet TE and Alston JA. Cysteine oxidation of tau and microtubule-associated protein-2 by peroxynitrite: modulation of microtubule assembly kinetics by the thioredoxin reductase system. J Biol Chem, 2004; 279(33):35101-35105. 
44. Chalmers CJ, Gilley R, March HN, Balmanno K, Cook SJ. The duration of ERK1/2 activity determines the activation of c-Fos and Fra-1 and the composition and quatitative transcriptional output of AP-1. Cellular Signalling, 2007; 19:695704.

\section{ABBREVIATIONS LIST:}

ASK-1, apoptosis signal regulating kinase-1; BSA, bovine serum albumin; cDDP, cisplatin, cisplatinum(II)diammine dichloride; CEU, $N$-aryl$N^{\prime}$-(2-chloroethyl)ureas; CEU-022, 4-tert-butylchloroethylurea; CEU-025, 4-cyclohexylchloroethylurea; CEU-098, 4-iodochloroethylurea; COL, colchicine; $\mathrm{Vb}$, vinblastine; ERK, extracellular signal-regulated kinase; FA, focal adhesion; FAK, focal adhesion kinase; IEG, immediate early gene; JNK, c-jun $\mathrm{NH}_{2}$-terminal kinase; L-JNKI-1, L-stereoisomer of a peptide inhibitor of c-jun $\mathrm{NH}_{2}$-terminal Kinase; MAP, mitogen-activated protein; MIA, microtubule interfering agents; MT, microtubule; MAPK, mitogen-activated protein kinase; PD098059, 2-(2-amino-3-methoxyphenyl)chromen-4-one; SB203580, 4-(4fluorophenyl)-2-(4-methylsulfinylphenyl)-5-(4pyridyl)- $1 \mathrm{H}$-imidazole; PX-12, 1-methylpropyl 2imidazolyl disulfide; Trx-1, thioredoxin isoform.

\section{Supplementary Illustrations:}

A

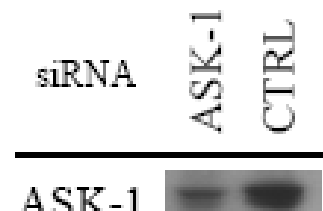

\section{B N2A}

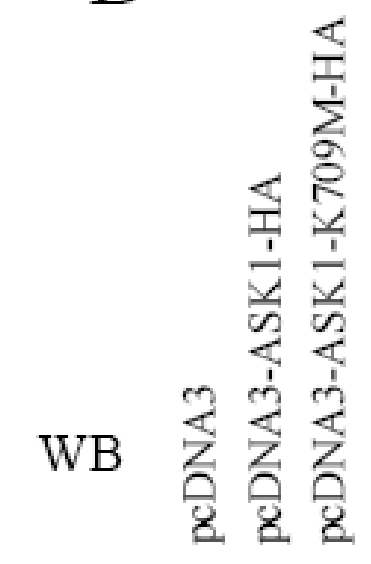

\section{HT1080}

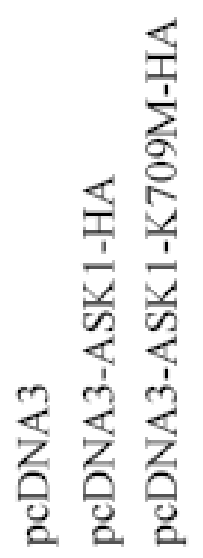

\section{ASK-1}

Supplementary Data 1. A) Western blot analysis of transfected HT1080 cells with siRNA CTRL or siRNA-ASK-1 before drug treatment. B) Western blot analysis of transfected cells with pcDNA3, pcDNA3-ASK1K709M-HA, and pcDNA3-ASK1-HA. 


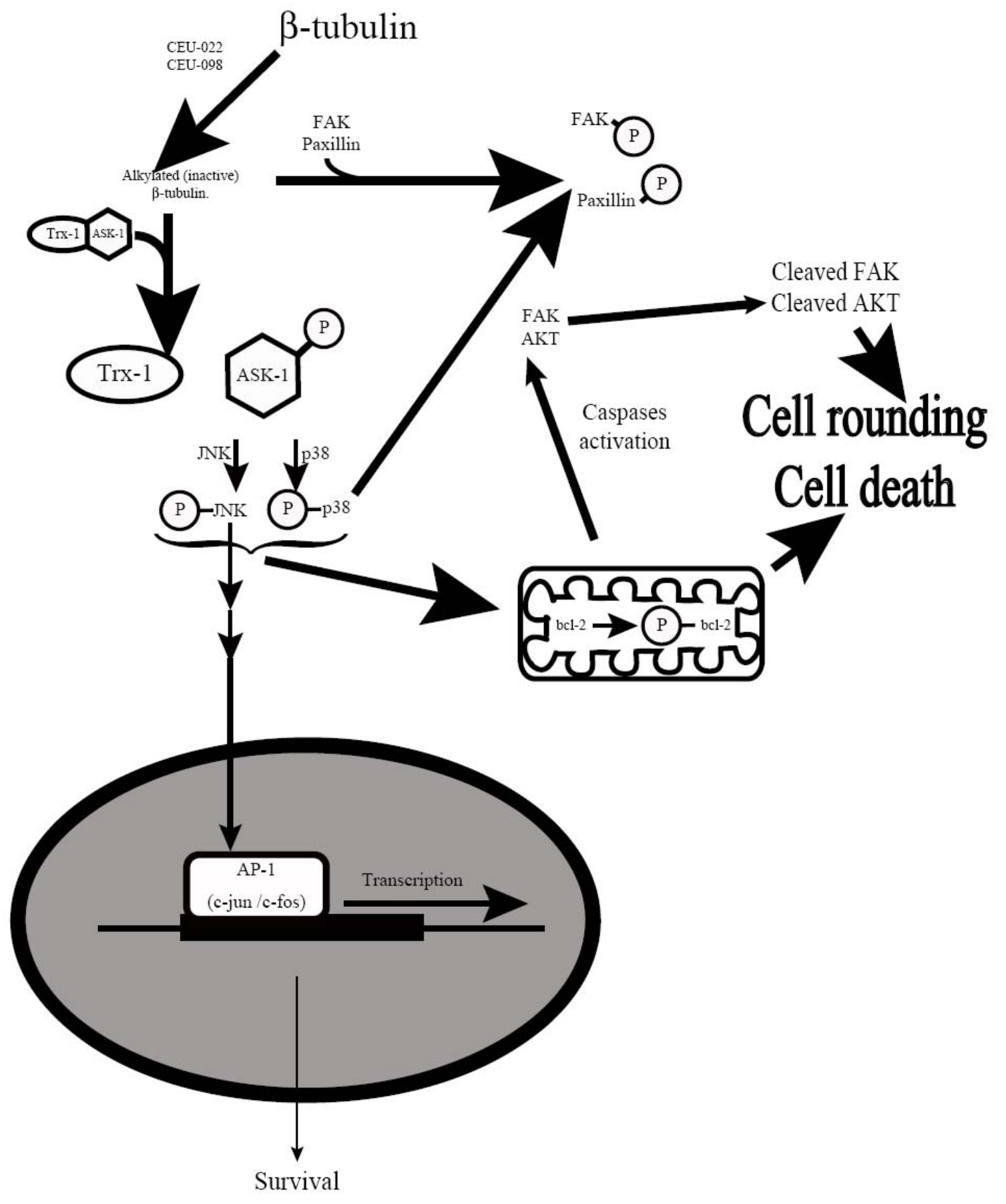

Supplementary Data 2. Model illustrating the signaling pathways activated by the MT-disrupting CEU and classical agents. MT disrupting agents trigger a rapid stress, such as actin contractility, and thus mimic an oxidative stress. As a result, the liberation of ASK-1 by the thioredoxin complex, and its subsequent activation through a phosphorylation, leads to the activation of the p38 and JNK. The non-MT-disrupting CEU do not activate the MAPK pathway presumably by the preservation of the thioredoxin/ASK-1 complex. Consequently, paxillin phosphorylation by the MAPKs leads to the FA disorganization. In addition, the antiapoptotic protein bcl-2 is phosphorylated and caspase-9, 7, -6 , and -3 are activated by the MAPKs. Prosurvival proteins such as FAK and Akt are cleaved through the caspases activation. These events lead to anoikis. 